\title{
Avaliação das características do líquido ruminal, hemogasometria, atividade pedométrica e diagnóstico de laminite subclínica em vacas leiteiras ${ }^{1}$
}

\author{
Mirian Rodrigues ${ }^{2}$, Maurício Deschk², Guilherme G.F. Santos ${ }^{3}$, Silvia H.V. Perri ${ }^{4}$, Victoria R. \\ Merenda $^{5}$, Carlos A. Hussni ${ }^{6}$, Ana Liz G. Alves ${ }^{6}$ e Celso A. Rodrigues ${ }^{6 *}$
}

\begin{abstract}
Rodrigues M., Deschk M., Santos G.G.F., Perri S.H.V., Merenda V.R., Hussni C.A., Alves A.L.G. \& Rodrigues C.A. 2013. [Evaluation of the characteristics of ruminal fluid, hemogasometry, pedometer activity and subclinical laminitis diagnosis in dairy cows.] Avaliação das características do líquido ruminal, hemogasometria, atividade pedométrica e diagnóstico de laminite subclínica em vacas leiteiras. Pesquisa Veterinária Brasileira 33(Supl.1):99-106. Departamento de Clínica Cirurgia Veterinária, Universidade Estadual Paulista, Faculdade de Medicina Veterinária e Zootecnia, Distrito de Rubião Jr s/n, Botucatu, SP 18618-970, Brazil. E-mail: rodriguesca@fmvz.unesp.br

The objectives of this study were to evaluate the characteristics of ruminal fluid, blood gas analysis, pedometer activity and suclinical laminitis occurrence, through the presence of secondary foot diseases in high production dairy cows, from a commercial herd. 200 Holstein cows originating from the same farm, located in Araçatuba/SP, Brazil, were divided into four groups, which are established from the daily milk production. Initially clinical examination of the cows was procedure, followed by sampling of rumen fluid, by esophageal tube. Fluid was evaluated for $\mathrm{pH}$, color, odor, consistency, sedimentation, flotation and methylene blue reduction test. Venous blood samples were also collected for blood gas analysis, in addition to collecting data from pedometrics (number of steps) and daily milk production. Data were tabulated and submitted to correlation analysis. No animal had reported changes in rumen $\mathrm{pH}$. Non-acid base imbalance were found, since the values of blood pH, $\mathrm{PCO} 2$, TCO2, HCO3- and BE were normal during hemogasimetric analysis. The pedometric was effective as a screening method to cows with foot diseases. It demonstrated reduction in the number of steps due to pain, correlated with lower milk production. However, the identification of foot lesions was only possible through specific digital clinical examination. The occurrence of $49.5 \%$ of herd foot problems was due to the risk factors present in the farm. The abrasive concrete and inadequate facilities, also associated with the possible occurrence of sub-acute ruminal acidosis, were observed as risk factors. However, sub-acute ruminal acidosis was undiagnosed by the methods used. The correlation between the values of ruminal $\mathrm{pH}$, and blood gas analysis pedometrics showed efficient for the early diagnosis of foot diseases and also in establishing the etiology of these diseases. Subclinical laminitis occurred primarily in cow's herd, considering the multifactorial etiology of this disease, occurrence and distribution of foot diseases diagnosed.
\end{abstract}

INDEX TERMS: Affections podal, bovine, subclinical laminitis, rumen fluid, subacute ruminal acidosis.

\footnotetext{
${ }^{1}$ Recebido em 16 de outubro de 2013.

Aceito para publicação em 4 de dezembro de 2013.

${ }^{2}$ Doutorando, Departamento de Cirurgia e Anestesiologia Veterinária, Faculdade de Medicina Veterinária e Zootecnia (FMVZ), Universidade Estadual Paulista (Unesp), Distrito de Rubião Júnior s/n, Botucatu, SP 18618970, Brasil. E-mails: mi_medvet@yahoo.com.br, mdeschk@hotmail.com

${ }^{3}$ Mestrando, Departamento de Clínica, Cirurgia e Anestesiologia Veterinária, Faculdade de Medicina Veterinária (FMV), Universidade Estadual Paulista (Unesp), Rua Clóvis Pestana 793, Araçatuba, SP 16050-680, Brasil. E-mail: guilherme_fabretti@hotmail.com
}

\footnotetext{
${ }^{4}$ Docente do Departamento de Apoio, Produção e Saúde Animal, FMV-Araçatuba, Unesp, Araçatuba, SP. E-mail: shvperri@fmva.unesp.br

${ }^{5}$ Bolsista de Iniciação Científica FAPESP, Departamento de Cirurgia e Anestesiologia Veterinária, Faculdade de Medicina Veterinária e Zootecnia (FMVZ), Unesp, Distrito de Ruião Junior s/n, Cx. Postal 560, Botucatu, SP 18618-970l. E-mail: victoriarocham@hotmail.com

${ }^{6}$ Docente do Departamento de Cirurgia e Anestesiologia Veterinária, Faculdade de Medicina Veterinária e Zootecnia (FMVZ), Unesp, Distrito de Ruião Júnior s/n, Caixa Postal 560, Botucatu, SP 18618-970. *Autor para correspondência: rodriguesca@fmvz.unesp.br
} 
RESUMO.- Este estudo objetivou avaliar as características do líquido ruminal, hemogasometria, atividade pedométrica e ocorrência laminite subclínica, por meio da presença de enfermidades podais secundárias, em vacas leiteiras de alta produção, provenientes de um rebanho comercial. Foram avaliadas 200 vacas holandesas, oriundas da mesma propriedade, localizada na região de Araçatuba, SP, divididas em quatro grupos, sendo estes estabelecidos a partir da produtividade diária. Inicialmente procedeu-se o exame clínico dos animais, seguido da colheita de amostras do líquido ruminal, por meio de sondagem esofágica, sendo este avaliado quanto ao $\mathrm{pH}$, cor, odor, consistência, sedimentação, flutuação e prova de redução pelo azul de metileno. Também foram colhidas amostras de sangue venoso para hemogasometria, além da coleta dos dados da pedometria (número de passos) e produção de leite diária das vacas. Os dados obtidos foram tabulados e submetidos à análise de correlação. Nenhum animal avaliado apresentou alterações no $\mathrm{pH}$ ruminal, bem como não foram encontrados distúrbios do desequilíbrio ácido básico, pois os valores de pH sanguíneo, PCO2, TCO2, HCO3- e EB estavam dentro da normalidade, durante a análise hemogasométrica. A pedometria foi efetiva como método de triagem para as vacas acometidas de afecções podais, pois se observou a redução no número de passos devido à dor, correlacionada a menor produção leiteira. Contudo, a identificação destas afecções, somente foi possível mediante exame clínico específico dos dígitos. A ocorrência das afecções podais em $49,5 \%$ do rebanho deveu-se aos fatores de riscos presentes na propriedade, como o concreto abrasivo e instalações inadequadas, associados também a possível ocorrência de acidose ruminal subaguda, não diagnosticada pela metodologia utilizada. A correlação entre os valores do $\mathrm{pH}$ ruminal, pedometria e hemogasometria se mostrou eficiente para o diagnóstico precoce das afecções podais e também no estabelecimento da etiologia destas enfermidades. A laminite subclínica acometeu primariamente as vacas do rebanho, considerando a etiologia multifatorial desta afecção, ocorrência e distribuição das enfermidades podais diagnosticadas.

TERMOS DE INDEXAÇÃO: Acidose ruminal subaguda, afecções podais, bovinos, laminite subclínica, líquido ruminal.

\section{INTRODUÇÃo}

O Brasil registrou nas últimas três décadas significativo crescimento na produção de leite, obtido principalmente pela globalização do mercado, levando os produtores a investir em novas tecnologias e melhoramento genético, caracterizado por animais de alto valor zootécnico e de baixa rusticidade. Contudo, concomitantemente com o uso destas tecnologias ocorreu uma elevação da incidência de enfermidades do sistema reprodutivo, glândula mamária e do aparelho locomotor (Silveira et al. 1999).

A necessidade de intensificar a produção de carne e leite também resultou em grandes mudanças na nutrição dos bovinos. Surgiram novas variedades de forrageiras, modificações nas quantidades fornecidas. Assim, maiores volumes foram oferecidos, objetivando uma maior produtividade (Borges et al. 2002). Desta forma, enfermidades como a acidose ruminal subaguda (ARS) passaram a ser relevantes em rebanhos de exploração intensiva (Gianesella 2008).

A ARS representa um dos maiores problemas na exploração dos bovinos leiteiros, capaz de provocar prejuízos econômicos inestimáveis, prejudicando não só a produtividade e a rentabilidade da propriedade, mas também, o bem estar animal (Gianesella 2008). Esta enfermidade apresenta sinais secundários como a laminite, pobre condição corporal, ruminite, mastite, metrite entre outras (Nordlund et al. 2004, Krause \& Oetzel 2005, Gozho et al. 2007, Alzahal et al. 2008, Gianesella 2008).

A ARS apresenta sinais clínicos discretos, tornando difícil sua detecção e fazendo com que o diagnóstico dependa da percepção dos sinais clínicos secundários dentro do rebanho (Nordlund et al. 2004).

Embora a relação entre ARS e laminite ainda não esteja totalmente esclarecida, uma das teorias correlaciona o dano causado no epitélio ruminal pela ARLS, permitindo a absorção de histaminas e endotoxinas que danificam a circulação sanguínea levando a condição comumente chamada de laminite (Stone 2004).

A laminite é uma condição debilitante que afronta a sustentabilidade dos sistemas de produção e causa além de dor para o animal, consequências sociais e perdas econômicas inestimáveis (Bicalho et al. 2009). A enfermidade é tida como a terceira causa de descarte mais comum das afecções podais depois de problemas reprodutivos e mastite (Ferreira et al. 2005, Silva et al. 2006, Albuquerque et al. 2009, Sagliyan et al. 2010). Porém, apresenta-se em segundo lugar, após a mastite como a doença mais onerosa na indústria de laticínios (Bicalho et al. 2009).

Nos últimos anos, ampliou-se o entendimento dos mecanismos fisiopatológicos envolvidos na patogênese dos transtornos dos dígitos dos bovinos, especialmente sobre a laminite na forma subclínica ou assintomática (Mulling et al. 2006). Sua relação com as demais enfermidades e também com o bem estar animal, tem sido intensamente estudada (Rama 2006).

Este estudo teve por objetivo avaliar as características do líquido ruminal, hemogasometria, atividade pedométrica e diagnóstico de laminite subclínica, por meio da ocorrência de enfermidades podais secundárias, em vacas leiteiras de alta produção, provenientes de um rebanho comercial.

\section{MATERIAL E MÉTODOS}

Animais e grupos experimentais. Foram utilizadas 200 vacas holandesas, oriundas da mesma propriedade leiteira, localizada na região de Araçatuba, estado de São Paulo, separadas em quatro lotes diferentes:

Lote 1: 70 vacas com produção de leite superior a 20 litros/ dia e com dias em lactação (DEL) maior que 100 dias;

Lote 2: 48 vacas com produção de leite superior a 20 litros/ dia e DEL até 100 dias;

Lote 3: 28 vacas com produção de leite superior a 20 litros/ dia e com contagem de células somáticas (CCS) acima de 400 mil células/ml (mastite);

Lote 4: 54 vacas com produção inferior a 20 litros/dia e DEL superior a 100 dias.

Os lotes descritos acima apresentavam variações na dieta diária, conforme descrito no Quadro 1. 
Quadro 1. Quantidade em quilos dos constituintes da dieta fornecida três vezes ao dia aos animais nos diferentes lotes

\begin{tabular}{lcccc}
\hline Componentes & Lote 1 & Lote 2 & Lote 3 & Lote 4 \\
\hline Ração & $10 \mathrm{~kg}$ & $10 \mathrm{~kg}$ & $10 \mathrm{~kg}$ & $5 \mathrm{~kg}$ \\
Feno & $1,5 \mathrm{~kg}$ & $1,5 \mathrm{~kg}$ & $1,5 \mathrm{~kg}$ & $\cdot$ \\
Uréia & $0,100 \mathrm{~kg}$ & $0,100 \mathrm{~kg}$ & $0,100 \mathrm{~kg}$ & $0,100 \mathrm{~kg}$ \\
Silagem de milho & $38,0 \mathrm{~kg}$ & $34,0 \mathrm{~kg}$ & $38,0 \mathrm{~kg}$ & $38,0 \mathrm{~kg}$ \\
Total & $49,6 \mathrm{~kg}$ & $45,6 \mathrm{~kg}$ & $49,6 \mathrm{~kg}$ & $43,1 \mathrm{~kg}$
\end{tabular}

Exame físico. Todos os animais foram conduzidos ao brete, identificados e avaliados clinicamente quanto à frequência cardíaca, frequência respiratória, movimentos ruminais, temperatura retal e turgidez da pele, sendo este último mensurado o grau de desidratação, por meio do pregueamento da pele na região escapular.

O diagnóstico clínico das lesões podais foi feito pela inspeção dos cascos, tanto dos animais claudicantes quanto dos não claudicantes, observando-se apoio, muralha, espaço interdigital e após o levantamento do membro, sola do casco. Durante o exame, os animais tiveram os cascos limpos e quando necessário, foi realizado o casqueamento, objetivando a identificação e registro das afecções.

Colheita e análise das amostras de sangue. As amostras de sangue venoso foram obtidas mediante venopunção jugular. Calibrou-se o analisador sanguíneo clínico portátil (I-STAT Portable Clinical Analyser $)^{7}$ diariamente e, anteriormente as mensurações, conforme as recomendações do fabricante. Os cartuchos CG8 ${ }^{8}$ utilizados nas avaliações hemogasométrica foram conservados em geladeira a temperatura de $2-8^{\circ} \mathrm{C}$ e, acondicionados em caixa térmica de poliestireno expandido (Isopor ${ }^{\circledR}$ ) com gelo, no momento da sua utilização. Cuidadosamente uma pequena fração da amostra coletada foi destinada ao cartucho, o qual foi inserido no analisador sanguíneo, que solicitava o tipo da amostra sanguínea (arterial ou venosa) e a temperatura retal do animal no momento da colheita. Tais informações foram essenciais para a correção dos valores padrões fornecidos pelo aparelho que realizou as mensurações de glicose, sódio, potássio, cálcio ionizado, hematócrito, hemoglobina, pH, PCO2 (pressão parcial de dióxido de carbono sanguíneo), PO2 (pressão de oxigênio sanguíneo), TCO2 (total de dióxido de carbono sanguíneo), HCO3 (bicarbonato), EB (excesso básico) e SO2 (saturação sanguínea de oxigênio), sendo os dados obtidos imediatamente impressos e armazenados.

Colheita e análise do líquido ruminal. Na propriedade, fornecia-se a dieta três vezes ao dia aos animais, sendo: às 6 horas da manhã, após a primeira ordenha; às 11 horas e 30 minutos e a última fornecida às 16 horas, após a segunda ordenha. A colheita das amostras foi realizada no período da manhã, logo após a primeira ordenha. Este horário foi o de escolha para não atrapalhar $\mathrm{o}$ andamento rotineiro das atividades na propriedade. A ordenha se iniciava pelo lote 1 , seguido dos lotes 2 e 4 e, por último o lote 3 , devido aos casos de mastites. As coletas das amostras de líquido ruminal foram realizadas mediante a introdução de uma sonda esofágica, adaptada a uma bomba de vácuo (Bomba de sucção ruminal - H. Hauptner, Solingen $)^{9}$. A fim de diminuir a contaminação pela saliva nas amostras e minimizar a interferência nos valores do $\mathrm{pH}$. Foram desconsiderados os primeiros $200 \mathrm{ml}$ de líquido ruminal, sendo aproveitados os volumes subsequentes. Após a obtenção das amostras, estas foram imediatamente transferidas para garrafas térmicas individuais, previamente aquecidas com água à temperatura de $39^{\circ} \mathrm{C}$, sendo estas fechadas logo após o envase, objetivando evitar mudanças bruscas na temperatura e contato com o ar atmosférico. As amostras permaneceram nas respectivas garrafas, sendo imediatamente analisadas as características: pH ruminal, cor, odor, consistência e prova de redução do azul de metileno (PRAM).
A mensuração do pH do líquido ruminal foi realizada mediante a utilização de um phmetro digital portátil ${ }^{10}$, previamente calibrado. Logo após, foram dispostos $20 \mathrm{ml}$ de líquido ruminal em duas provetas de $50 \mathrm{ml}$, para se avaliar as características de cor, odor, consistência e a prova de redução do azul de metileno, onde se adicionou $1 \mathrm{ml}$ do azul de metileno a $0,03 \%$ em $20 \mathrm{ml}$ de suco. Foi considerado suco ruminal com atividade bacteriana "ativa" o que obteve um tempo de redução do azul de metileno em até 3 minutos, "média" naquele que obteve a redução de 3 a 6 minutos e "reduzida" no qual foi constatado tempo superior a 6 minutos.

Avaliação pedométrica. A análise comportamental das vacas fez uso de um pedômetro ${ }^{11}$, afixado no terço distal do metatarso dos animais. 0 referido equipamento fornecia informações por rádio frequência para um leitor automático, sendo estes dados registrados e processados pelo respectivo software ${ }^{12}$ do fabricante. Os dados incluíam o número de passos por hora e a quantidade de leite diária produzida. Os dados considerados para a análise neste estudo compreenderam média dos sete dias, anteriores à coleta de amostras e manipulação dos animais.

Análise estatística. Os dados das aferições numéricas (produção de leite, pH sanguíneo e gases sanguíneos) foram submetidos à análise de variância para comparar os lotes, sendo as médias comparadas pelo teste de Tukey. Os dados foram testados quanto à normalidade e homogeneidade de variâncias pré-requisitos necessários para a análise de variância. As análises estatísticas do excesso de base (EB) e dos escores da prova de redução do azul de metileno foram realizadas pelo teste de Kruskal-Wallis para comparar os lotes, seguido do teste de comparações múltiplas de Dunn. Para verificar diferenças entre os lotes em relação ao movimento ruminal normal e alterado foi utilizado o teste Qui-quadrado. Os resultados estatísticos foram considerados significativos quando $\mathrm{P}<0,05$. As análises foram executadas empregando-se o programa $\mathrm{SAS}^{13}$ (Statistical Analysis System).

\section{RESULTADOS}

\section{Exame físico}

Os vacas avaliados apresentavam em média 4,4 anos de vida, variando de 2 a 12 anos. 0 exame físico das vacas revelou que a frequência cardíaca (FC) se manteve na média de 87,3 batimentos por minuto (bpm), variando de 48 a $120 \mathrm{bpm}$. A frequência respiratória (FR) teve média de 39 movimentos por minuto (mpm), variando de 20 a 88 mrm. A média da temperatura retal (TR) foi de $38,7^{\circ} \mathrm{C}$, com mínimo de $38^{\circ} \mathrm{C}$ e máximo de $40^{\circ} \mathrm{C}$. 0 tugor de pele foi $<2$ segundos em todos os animais, sendo $>2$ segundos em apenas uma vaca. A média dos movimentos ruminais (MR) foi de 2,02 MR/2 minutos. 0 lote 1 apresentou 72,9\% dos animais com MR normal, sendo o restante, $27,1 \%$ reduzido. 0 lote 2 não diferiu do lote 1 , tendo $75 \%$ dos animais normais

${ }^{7}$ I-STAT - Portable Clinical Analyser, Abbott Laboratories, Illinois, EUA.

8 I-STAT cartucho CG8 - Cartuchos para análises sanguíneas, Abbott Laboratories, Illinois, EUA.

${ }^{9}$ Bomba de sucção rumenal - H. Hauptner, Solingen, Alemanha.

${ }^{10}$ Phmetro digital portátil, Modelo HI 9126 - Hanna Instruments Brasil, São Paulo, Brasil.

${ }^{11}$ Pedometer Plus tags - AfiMilk, Kibbutz Afikim, Israel.

${ }^{12}$ Version 0.6 of the Tag Reader Unit, and software version 0.2 of the Tag RPU - AfiMilk, Kibbutz Afikim, Israel.

${ }^{13}$ SAS Institute Inc. - The SAS System, release 9.2. SAS Institute Inc., Cary, NC, 2008. 
e $25 \%$ reduzido. 0 lote 3 obteve $50 \%$ dos animais com MR normal e $50 \%$ reduzido, não diferindo do lote 4 que apresentou $53,7 \%$ dos animais com MR normal e 46,3\% reduzido, onde o valor de $p=0,0203$ foi significante.

0 rebanho apresentou elevada incidência de afecções podais pois $49,5 \%$ dos animais, ou seja, 98 animais apresentaram algum tipo de enfermidade. As afecções encontradas no rebanho (Fig.1) foram 0,5\% (1 animal) pododermatite séptica, $1 \%$ ( 2 animais) artrite séptica, 3,5\% (7 animais) úlcera de sola, 5,5\% (11 animais) úlcera de pinça, 7\% (14 animais) dermatite digital, 9,5\% (19 animais) hemorragia de sola, 10\% (20 animais) doença da linha branca e 12,5\% (25 animais) erosão de talão. A ocorrência das lesões foi maior nos membros pélvicos com 95 animais (96\%) do que nos membros torácicos com 4 animais (4\%).

\section{Afecções podais no rebanho}

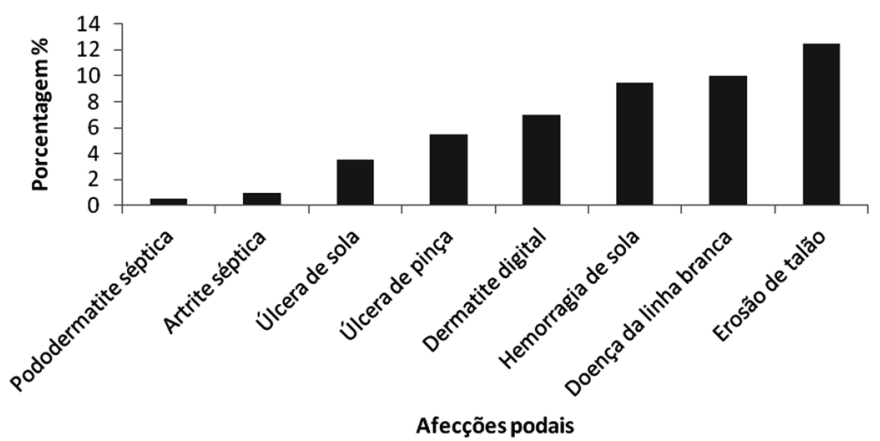

Fig.1. Porcentagem das afecções podais diagnosticadas no rebanho.

\section{Exame hemogasométrico}

0 valor do $\mathrm{pH}$ sanguíneo se apresentou dentro da normalidade de 7,35 e 7,45 com as seguintes médias e desvio padrão para cada lote: lote $1(7,40 \pm 0,04)$, lote 2 $(7,38 \pm 0,04)$, lote $3(7,40 \pm 0,03)$ e lote $4(7,39 \pm 0,03)$, não apresentando diferença entre eles. Os valores da pressão parcial de dióxido de carbono sanguíneo $\left(\mathrm{PCO}_{2}\right)$ se mantiveram nas médias de 41,34 $\pm 3,65 \mathrm{mmHg}$ (lote 1 ), $42,28 \pm 5,18 \mathrm{mmHg}$ (lote2), 41,05 $\pm 4,41 \mathrm{mmHg}$ (lote 3) e $43,13 \pm 6,83 \mathrm{mmHg}$ (lote 4 ). Os valores de total de dióxido de carbono sanguíneo $\left(\mathrm{TCO}_{2}\right.$ ) dos lotes $1,2,3$ e 4 foram respectivamente $26,41 \pm 2,06 \mathrm{mmol} / \mathrm{L}, 26,02 \pm 2,80 \mathrm{mmol} / \mathrm{L}$, $26,32 \pm 2,98 \mathrm{mmol} / \mathrm{L}$ e $27,67 \pm 2,36 \mathrm{mmol} / \mathrm{L}$, sendo o lote 2 diferente do lote 4 . Os valores de bicarbonato $\left(\mathrm{HCO}_{3}\right)$ foram $25,26 \pm 2,01 \mathrm{mmol} / \mathrm{L}$ (lote 1 ), $24,82 \pm 2,67 \mathrm{mmol} / \mathrm{L}$ (lote 2), $25,18 \pm 2,85 \mathrm{mmol} / \mathrm{L}$ (lote 3 ) e $26,49 \pm 2,25 \mathrm{mmol} / \mathrm{L}$ (lote 4 ), sendo os lotes 2 e 3 diferentes do lote 4 . Os valores de saturação sanguínea de oxigênio $\left(\mathrm{SO}_{2}\right)$ em cada lote foram 49,97 $\pm 9,58$ (lote 1), 51,90 $\pm 8,74$ (lote 2), 51,82 $\pm 10,06$ (lote 3) e 53,96 $\pm 7,90$ (lote 4). Na análise do Excesso básico (EB), os lotes apresentaram as seguintes médias e desvios padrões: lote $1(0,93 \pm 2,37 \mathrm{mmol} / \mathrm{L})$, lote $2(0,27 \pm 2,94 \mathrm{mmol} / \mathrm{L})$, lote $3(0,86 \pm 3,11 \mathrm{mmol} / \mathrm{L})$ e lote $4(2,02 \pm 2,42 \mathrm{mmol} / \mathrm{L})$, onde o lote 2 foi diferente do 4 .

\section{Análises do líquido ruminal}

No presente estudo, o $\mathrm{pH}$ ruminal teve como valor mínimo 5,96 e máximo 7,38, obtendo a média de 6,81 (Quadro 2). A coloração do líquido intercalou entre castanho esverdeado e castanho amarelado, caracterizando respectivamente $65,8 \%$ e $34,2 \%$ dos animais. 0 odor variou entre aromático, ácido e repugnante, sendo respectivamente $96,5 \%, 3 \%$ e $0,5 \%$ para este aspecto. A consistência foi em $100 \%$ dos animais considerada pouco viscosa.

Na prova de redução pelo azul de metileno (PRAM), todos os lotes apresentaram maior número de animais com suco ruminal classificado como ativo (tempo de redução de até 3 minutos), sendo $88 \%$ no lote $1,80 \%$ para o lote 2 , $96,4 \%$ no lote 3 e $50 \%$ no lote 4 . A porcentagem de animais apresentando suco ruminal com atividade bacteriana média (tempo de redução de 3 a 6 minutos) foi de 10\%, 17\%, $3,6 \%$ e $50 \%$, respectivamente para os lotes $1,2,3$ e 4 . A ocorrência de suco ruminal com atividade bacteriana reduzida (tempo de redução maior que 6 minutos) nos lotes 1 $(1,4 \%), 2(2,1 \%), 3(0 \%)$ e $4(0 \%)$. Na amostragem, onde se correlaciona a PRAM com os lotes, fica evidente que existe diferença significativa entre estes. Os lotes 1, 2 e 3 são iguais e diferem do lote 4 (Quadro 3).

\section{Análise pedométrica}

$\mathrm{Na}$ análise pedométrica se observa uma correlação positiva entre o número de passos e a produção de leite, ou seja, quanto menor o número de passos, menor a produção de leite. Nota-se também, diferença significativa da produção de leite entre os lotes, onde a maior produção foi no lote 2 com média de $27,3 \pm 3,7$, diferindo do lote 1 , com média de $23,6 \pm 4,6$ e do lote 3 com média de $21,5 \pm 6,2$, que por sua vez divergem do lote 4 , com média de $11,8 \pm 2,6$.

\section{Quadro 2. Média $(\bar{X})$ e desvio padrão (S) do pH ruminal,} segundo o lote

\begin{tabular}{lc}
\hline Lote & $\mathrm{pH}$ ruminal $(\overline{\mathrm{X}} \pm \mathrm{S})$ \\
\hline 1 & $6,68 \pm 0,32^{\mathrm{b}}$ \\
2 & $6,71 \pm 0,28^{\mathrm{ab}}$ \\
3 & $6,77 \pm 0,35^{\mathrm{ab}}$ \\
4 & $6,86 \pm 0,31^{\mathrm{a}}$ \\
\multicolumn{2}{l}{ Médias seguidas de letras distintas diferem entre si pelo teste de Tukey } \\
$(\mathrm{p}<0,05)$.
\end{tabular}

Quadro 3. Distribuição de frequências dos animais segundo a prova de redução do azul de metileno (PRAM) e lote

\begin{tabular}{lccccccccc}
\hline PRAM & \multicolumn{10}{c}{ Lote } \\
\cline { 2 - 11 } & \multicolumn{1}{c}{1} & \multicolumn{1}{c}{2} & \multicolumn{2}{c}{3} & \multicolumn{2}{c}{4} \\
\hline Normal & 62 & 88,6 & 38 & 80,9 & 27 & 96,4 & 27 & 50,0 \\
Médio & 7 & 10,0 & 8 & 17,0 & 1 & 3,6 & 27 & 50,0 \\
Reduzido & 1 & 1,4 & 1 & 2,1 & - & - & - & - \\
Total & 70 & 100,0 & 47 & 100,0 & 28 & 100,0 & 54 & 100,0
\end{tabular}

$\mathrm{P}<=0,0001$.

\section{DISCUSSÃO}

As vacas apresentaram de forma geral, um bom estado físico, apresentando a FC (87,3 bpm) e FR (39 mrm) um pouco acima dos valores de referência, sendo a normalidade respectivamente de 65 a $80 \mathrm{bpm}$ e 24 a $36 \mathrm{mrm}$ segundo Dirksen (2008). Estes valores aumentados provavelmente 
se devem as altas temperaturas $\left({ }^{\circ} \mathrm{C}\right)$ registradas e as variações de umidade (\%) no período em que ocorreu o estudo, variando respectivamente de $16,8-35,3^{\circ} \mathrm{C}$ e $30-89 \%$. A temperatura retal (TR) com média de $38,7^{\circ} \mathrm{C}$ se encontrava dentro dos valores normais de $38-39,5^{\circ} \mathrm{C}$, propostos por Feitosa (2008). Apenas um animal apresentou desidratação, fundamentado pelo exame da elasticidade da pele sobre o dorso do animal, com tempo de pregueamento superior a dois segundos, associado a não obtenção do líquido ruminal, quando da sondagem.

A média dos movimentos ruminais (MR) foi de 2,02 $\mathrm{MR} /$ minuto, estando dentro dos valores normais de 2 a 3 MR/2 minutos citados por Dirksen (2008), contudo houve diferença estatística entre os lotes. Os lotes $1(72,9 \%)$ e 2 $(75,0 \%)$, apresentaram um maior número de animais normais com relação ao MR do que os lotes $3(50 \%)$ e $4(53,7)$.

0 rebanho apresentou uma grande porcentagem de vacas $(49,5 \%)$ acometidas por afecções podais, assim como encontrado por Cruz et al. (2001), que relatam prevalência de $50,2 \%$ nos bovinos analisados. Nas avaliações dos dígitos, as principais afecções encontradas neste estudo foram doenças secundárias a laminite. Sendo estas resultantes de manifestações podais, como isquemia e degeneração laminar. Estes fenômenos originam cascos mais frágeis e sensíveis e, consequentemente suscetíveis a traumas, como descreveu Nicoletti (2004). Estas condições elevam a ocorrência lesões secundárias, como úlcera de pinça, úlcera de sola, hemorragia de sola, doença da linha branca e erosão de talão, conforme se observou nos animais avaliados.

A laminite subclínica é o principal fator predisponente para a ocorrência da úlcera de sola e doença da linha branca (Belge et al. 2005). A hipótese de que a laminite apresentava alta prevalência no rebanho, está embasada no tipo e percentual das afecções observadas, onde a ocorrência de erosão de talão foi de $12,5 \%$, seguida por $10 \%$ de doença da linha branca, 9,5\% hemorragia de sola, $7 \%$ dermatite digital, 5,5\% úlcera de pinça, 3,5\% úlcera de sola, $1 \%$ artrite séptica e pododermatite séptica com $0,5 \%$. Estes achados diferem de Albuquerque et al. (2009) que relataram a doença da linha branca como sendo a de maior ocorrência em seu estudo e Cruz et al. (2001) que encontraram uma prevalência maior de dermatite digital no rebanho. Ferreira et al. (2004) observaram abscessos de sola e talão e doença da linha branca como as alterações mais frequentes em um rebanho leiteiro. Enquanto que Belge et al. (2005) descreveram a hemorragia de sola como a afecção mais frequentemente observada.

Estes achados ocorrem principalmente devido ao modo de criação dos animais confinados, que permanecem o tempo todo sobre piso de concreto, sendo submetidos a caminhadas diárias nesta superfície até o galpão de ordenha, estando em contato também com fezes e umidade. Estas condições contribuem para desgaste dos cascos e consequentemente a ocorrência de lesões podais, como descreveram Albuquerque et al. (2009). A maioria das afecções podais, mais exatamente $96 \%$, acometiam os membros pélvicos nas vacas avaliadas, assim como encontrado por Murray et al. (1996), Molina et al. (1999), Silva et al. (2001), Machado et al. (2008) e Cunha (2010). 0 maior en- volvimento dos membros pélvicos nas afeções podais pode ser devido à alterações conformacionais, originadas principalmente pelo volume e posicionamento do úbere, causando maior pressão sobre os dígitos laterais dos membros pélvicos. Desta forma, predispondo-o a lesões, conforme relatam Silva et al. (2006), Machado et al. (2008) e Cunha (2010). Outra explicação seria devido ao maior contato dos dígitos dos membros pélvicos, com matéria orgânica, como descrevem Martins et al. (2002).

$\mathrm{Na}$ análise hemogasométrica, o aparelho portátil i-STAT (Portable Clinical Analyser) foi de ótima utilização, pois as análises foram realizadas a campo instantaneamente após a colheita, sem que houvesse nenhuma interferência nas amostras, assim como descrito por Lisbôa et al. (2002), Silverman \& Birks (2002) e Sucupira \& Ortolani (2003), além de fornecer resultados semelhantes com os fornecidos pelos hemogasômetros convencionais, como descrito por Peiró et al. (2010).

As análises foram realizadas a partir do sangue venoso, pois além da facilidade de colheita também produziram resultados semelhantes quando comparados com os resultados obtidos na utilização do sangue arterial, conforme descreve Sucupira \& Ortolani (2003).

Neste estudo, não foram encontrados distúrbios do desiquilíbrio ácido básico, pois os valores de $\mathrm{pH}$ sanguíneo, $\mathrm{PCO}_{2}, \mathrm{TCO}_{2}$ e $\mathrm{HCO}_{3}^{-}$estavam dentro dos valores normais de referência segundo Kaneco et al. (1997) e Dohme et al. (2008). Além disso, os referidos autores relataram que o pH sanguíneo não é afetado pela ocorrência de ARS. Meyer et al. (1995) descreveram que a interpretação dos resultados de $\mathrm{TCO}_{2}$ é limitada, pois seus valores são diretamente dependentes das influências metabólicas e respiratórias, fato este também observado nos resultados obtidos nesta análise.

Os valores de EB estão dentro da normalidade citada por Ortolani (2003) e os valores de referência de $\mathrm{SO}_{2}$ para bovinos não foram encontrados. Na verdade, houve uma grande dificuldade de se estabelecer os valores de referência de hemogasometria em bovinos. 0 que se observou, foram valores muito diferentes de uma referência para a outra e informações incompletas, havendo a necessidade de mais estudos e da elaboração de valores de referências completos para o exame de hemogasometria em bovinos.

0 método de colheita do líquido ruminal realizado através de sonda oro-ruminal foi de rápida realização e não causou traumas aos animais, estando de acordo com Lavezzo et al. (1988), Radostits (2002), Salles et al. (2003), Campos et al. (2006), Cardoso (2007), Zilio et al. (2008), Lodge-Ivey et al. (2009) e Rangel et al. (2010). Estes autores indicaram o uso da sondagem por ser de baixo custo, permitir a realização do procedimento em um grande número de animais. Além disso, trata-se de um procedimento pouco invasivo, especialmente considerando o elevado valor zootécnico das vacas e a ausência de diferença nos resultados do $\mathrm{pH}$, quando comparado com o método da cânula ruminal.

As amostras, aproximadamente $300 \mathrm{ml}$, foram colhidas e armazenadas em garrafas térmicas individuais, previamente higienizadas e aquecidas com água quente e após a introdução do líquido ruminal, vedadas para se evitar mu- 
danças bruscas na temperatura e contato com o ar atmosférico, conforme descrito por Feitosa (2008). Este conduta se mostrou adequada à conservação e manutenção das amostras para posterior avaliação.

$0 \mathrm{pH}$ ruminal de todos os animais se manteve dentro dos valores normais citados por Dirksen (2008) de 5,5 a 7,4 , assim como descrito por Afonso \& Mendonça (2007) e Taijk et al. (2009). Esta normalidade pode estar associada ao tempo decorrido após a ingestão da dieta e coleta das amostras, pois segundo Feitosa (2008) logo após a ingestão, ocorre um aumento na digestão bacteriana, que por sua vez, aumenta a produção de ácidos graxos e consequentemente diminui os valores de $\mathrm{pH}$. Com o passar das horas, o $\mathrm{pH}$ vai se reestabelecendo podendo chegar a um valor maior que sete após 12 horas. Logo, no momento da colheita, alguns animais já haviam ingerido uma pequena quantidade da dieta, enquanto outros, ainda não. Ou seja, as amostras de fluído ruminal dos animais foram colhidas de acordo com a conveniência da fazenda e, consequentemente de forma não homogênea, dentro dos grupos. Devido a isso, a maioria dos animais no momento da colheita, já estavam com aproximadamente 12 horas sem a ingestão da dieta, explicando a normalidade encontrada nos valores do $\mathrm{pH}$ ruminal.

Com o tempo de colheita variável, não podemos afirmar categoricamente que as vacas não apresentavam ARS, analisando somente os valores de pH ruminal. Mediante as condições de colheita e analise, não foram observadas alterações no $\mathrm{pH}$ ruminal, porém a prova definitiva seria baseada na colheita de líquido ruminal por ruminocentese, 4 a 8 horas, momento no qual são alcançados os valores mínimos de $\mathrm{pH}$. Todavia, esta metodologia se apresentava inviável no rebanho comercial avaliado, pois o enquadramento e adequação ao manejo da propriedade foram pré-condições impostas para execução deste estudo.

0 descarte dos primeiros $200 \mathrm{ml}$ foi realizado buscando-se evitar a contaminação pela saliva, utilizando apenas o líquido subsequente para avaliação conforme Dirksen (2008) sugere. Desta forma, acredita-se que não houve influência significativa do método de colheita utilizado, nos valores do PH ruminal obtidos. Esta hipótese encontra respaldo nos resultados da PRAM e demais análises físicas do líquido ruminal.

As cores de liquido ruminal encontradas neste estudo foram castanho esverdeado e castanho amarelado que estão dentro da normalidade para animais que se alimentam com ração, feno e silagem de milho. A escala de cores do líquido ruminal depende da alimentação, variando de: oliva ou castanho esverdeado; verde puro para animais a pasto; amarelo acastanhado para animais com alimentação contendo silagem de milho ou palha; cinza leitoso em caso de acidose ou verde enegrecida, em casos patológicos (Dirksen 2008).

A classificação do odor do líquido ruminal neste estudo variou entre aromático, ácido e repugnante, sendo o odor aromático o mais encontrado com $96,5 \%$ dos animais. 0 odor segundo Feitosa (2008), pode ser classificado em aromático, ácido, repugnante, amoniacal ou inodoro.

Todos os animais apresentaram consistência pouco vis- cosa, provavelmente devido à propriedade se localizar em uma região onde se registram temperaturas elevadas, favorecendo uma maior ingestão de água pelos animais ou por inatividade microbiana, indicativo de acidose ruminal. A consistência normal do suco ruminal deve ser levemente viscosa e sua anormalidade varia entre muito viscosa, devido à contaminação com a saliva ou a ocorrência de timpanismo espumoso e pouco viscosa, devido a inatividade microbiana e jejum prolongado (Feitosa 2008).

A prova de redução do azul de metileno (PRAM), todos os lotes apresentaram maior número de animais normais, ou seja, com suco ruminal ativo. Esta análise reflete o metabolismo fermentativo anaeróbico das bactérias (Feitosa 2008). Uma microbiota altamente ativa, a redução do azul de metileno ocorrerá em até três minutos ou menos quando o alimento for rico em concentrado. Quando essa redução ocorre de três a seis minutos significa uma atividade microbiana média e acima de seis minutos para dietas de difícil digestão, anorexia prolongada e acidose ruminal (Dirksen 2008, Feitosa 2008).

As alterações no líquido ruminal são mais evidentes quando comparadas às alterações sanguíneas. Assim, caso as vacas apresentassem acidose ruminal, também seriam esperadas alterações nos valores do pH e gases sanguíneos, conforme relatam Bouba et al. (2000). Contudo, este fato não foi observado na avaliação pela hemogasometria.

Foi observada a redução no número de passos e como consequência a redução da produção de leite. Resultados semelhantes foram obtidos por Warnick et al. (2001), Hernandez et al. (2002) e Hernandez et al. (2005) que concluíram que animais que apresentam afecções podais consequentemente produzem menos leite quando comparadas a vacas sadias.

0 pedômetro pode ser considerado um método adequado de análise comportamental, objetivando avaliar a dor em bovinos, pois é notório que a sensibilidade nos cascos resultará em menor atividade e, consequentemente redução na atividade pedométrica, como descrito por Mazrier et al. (2006).

Reconhecidamente um dos comportamentos de dor nos animais é a relutância em se mover e redução da produtividade, como descrito por Underwood (2002), comprovando que quando menos o animal se locomove, menos produz.

Este estudo corrobora os relatos de Mulling et al. (2006) e Rama (2006), onde tanto a laminite, quanto as suas lesões secundárias, podem não ser associadas apenas a fatores nutricionais, mas multifatoriais. As instalações inadequadas da propriedade onde se realizou este projeto, reconhecidamente interferiram negativamente no conforto dos animais e implicavam em dificuldades para o alojamento e deslocamento das vacas. 0 concreto demasiadamente abrasivo e escadas de acesso são alguns fatores que influenciaram na ocorrência de afecções podais no rebanho, assim como descrito por Bond et al. (2012). Estes autores relataram que o confinamento é agravado por projetos inadequados, instalações desconfortáveis e de difícil acesso, onde os animais apresentam dificuldade de deitar e levantar.

Pode-se observar que o piso demasiadamente abrasivo, umidade, fezes e as caminhadas forçadas até a sala de orde- 
nha foram determinantes no desenvolvimento das afecções podais, assim como descrito por Albuquerque et al. (2009). Estas observações também são respaldadas pelos relatos de Somers et al. (2003), que encontraram mais de $80 \%$ das vacas expostas ao piso de concreto com algum tipo de doença podal.

A maioria dos cascos observados apresentaram o tecido córneo com excesso de desgaste, assim como observado por Cook et al. (2004) e Mulling et al. (2006). Assim, o casco se encontrava mais sensível e predisposto à ocorrência de lesões causadas pelo concreto, pedras e escadas. Bond et al. (2012) descreveram inclusive, que as lesões de abrasão ou pela má distribuição de peso podem ser denominadas de tecnopatias, devido ao emprego de tecnologia inadequada. Mason et al. (2012), após avaliaram um surto de claudicação em um rebanho, também concluíram que a claudicação estava associada a solas finas resultantes do desgaste excessivo do casco, como hipotetisado neste estudo.

Apesar das camas, onde os animais se deitavam para ruminar e descansar serem revestidas de borracha para maior conforto dos animais. Estas foram ajustadas de forma inapropriada, sendo muito curtas para o tamanho dos animais, causando transtorno tanto na hora de se deitar quanto na hora de levantar-se. Durante estes movimentos as vacas chocavam a coluna cervical no limitador de avanço do pescoço, causando traumas no local. Greenough (2007) afirma que uma vaca em decúbito aumenta a ruminação e a produção de saliva, auxiliando no tamponamento ruminal. Além disso, a posição quadrupedal por longo período aumenta a pressão interior do casco, diminuindo a perfusão sanguínea e consequentemente a diminuição da oxigenação e nutrição dos tecidos produtores de queratina. Assim, a falta de conforto observada nos cubículos, pode ser um dos fatores responsáveis pela incidência de afecções podais neste rebanho.

A propriedade contava com rodos automáticos que promoviam a limpeza dos galpões várias vezes ao dia, mantendo o ambiente com pouca quantidade de matéria orgânica. 0 piso de concreto frisado e as demais dependências também eram higienizados e contavam com um pedilúvio, utilizado com frequência. Assim, as condições de higiene não representaram um fator de risco relevante para as vacas do rebanho avaliado. Ferreira et al. (2005) relataram que animais em condições higiênicas precárias possuem maior risco de infecções podais, pois os cascos são higroscópicos e quando expostos a umidade e a pisos abrasivos elevam para $83 \%$ a taxa de desgaste $83 \%$, aumentando a ocorrência de lesões.

\section{CONCLUSÕES}

Neste estudo, não foi possível correlacionar a ocorrência de acidose ruminal subaguda com a presença de laminite subclinica, pois a metodologia utilizada na colheita de líquido ruminal não possibilitou a homogenicidade entre os grupos, o que pode ter influenciado os valores do $\mathrm{pH}$, devido ao tempo prolongado de jejum pré-colheita.

A hemogasometria das vacas se apresentou dentro dos padrões de normalidade, devendo ser criteriosamente avaliada, quando se desejar utilizá-la como método auxiliar no diagnóstico da acidose rumenal subaguda.
A pedometria se constituiu em um método adequado para sinalização de dor e afecções podais nas vacas, mediante alterações comportamentais, traduzidas pela redução do número de passos e consequentemente menor produção leiteira.

O concreto abrasivo, instalações inadequadas e, possivelmente a acidose ruminal subaguda, foram os fatores de riscos responsáveis pelas afeç̧ões podais.

A laminite subclinica acometeu primariamante os animais, considerando sua etiologia multifatorial, resultando nas afecções podais diagnosticadas, como erosão de talão, doença da linha branca, hemorragia de sola, dermatite digital, úlcera de pinça e sola, artrite séptica e pododermatite séptica.

Agradecimentos.- À Fundação de Amparo à Pesquisa do Estado de São Paulo (FAPESP) pela concessão da bolsa de Mestrado (Proc. 2011/043049), bolsa IC (Proc. 2012/16867-0) e pelo auxílio financeiro (Proc. 2012/06840-8) e ao Sítio 5 Mulheres, pela colaboração na realização deste estudo.

\section{REFERÊNCIAS}

Afonso J.A.G. \& Mendonça C.L. 2007. Acidose Láctica Ruminal, p.313-319. In: Riet-Correa F., Schild A.L., Lemos R.A.A. \& Borges J.R.J. (Eds), Doenças de Ruminantes e Eqüídeos. 3aㅡ ed. Pallotti, Santa Maria. 419p.

Albuquerque P.I., Ximenes F.H.B., Moscardini A.C.R., Gouvêa L.V., Mota A.L. A.A., Godoy R.F. \& Borges J.R.J. 2009. Caracterização das afecções podais em rebanho de gado holandês confinado. Ciênc. Anim. Bras. 1:46-52.

Alzahal O., Kebreab E., France J., Froetschel M. \& McBride B.W. 2008. Ruminal temperature may aid in the detection of subacute ruminal acidosis. J. Dairy Sci. 91:202-207.

Belge A., Bakir R., Gonenci R. \& Ormanci S. 2005. Subclinical laminitis in dairy cattle: 205 selected cases. Turkish J. Vet. Anim. Sci. 29:9-15.

Bicalho R.C., Machado V.S. \& Caixeta L.S. 2009. Lameness in dairy cattle: a debilitating disease or a disease of debilitated cattle? A cross- sectional study of lameness prevalence and thickness of the digital cushion. J. Dairy Sci. 92:3175-3184.

Bond G.B., Almeida R., Ostrensky A. \& Molento C.F.M. 2012. Métodos de diagnóstico e pontos críticos de bem-estar de bovinos leiteiros. Ciência Rural 42:1286-1293.

Borges N.C., Silva L.A.F., Fioravanti M.C.S., Cunha P.H.J., Moraes R.R., Guimarães P.L. \& Martins M.E.P. 2002. Avaliação do suco ruminal de bovinos “a fresco" e após 12 horas de conservação. Ciênc. Anim. Bras. 3:57-63.

Bouba J., Quiroz-Rocha G.F. \& González F.H.D. 2000. Importância da coleta e análise de líquido ruminal e urina, p.13-16. In: González F.H.D., Borges J.B. \& Cecin M. (Eds), Uso de Provas de Campo e Laboratório Clínico em Doenças Metabólicas e Ruminais dos Bovinos. UFRGS, Porto Alegre. 61p.

Campos R., González F., Coldebella A. \& Cardoso F. 2006. Indicadores do ambiente ruminal e suas relações com a composição do leite e células somáticas em diferentes períodos da primeira fase da lactação em vacas de alta produção. Ciência Rural 36:525-530.

Cardoso F.C. 2007. Deslocamento de abomaso à esquerda em vacas leiteiras de alta produção: variações no hemograma, indicadores bioquímicos sanguíneos e do funcionamento ruminal. Dissertação de Mestrado em Ciências Veterinárias, Faculdade de Medicina Veterinária, Universidade Federal do Rio Grande do Sul, Porto Alegre. 48p.

Cook N.B., Nordlund K.V. \& Oetzel G.R. 2004. Environmental influences on claw horn lesions associated with laminitis and subacute ruminal acidosis in dairy cows. J. Dairy Sci. 87:E36-E46.

Cruz C., Driemeier D., Cerva C. \& Corbellini L.G. 2001. Clinical and epidemiological aspects of bovine digital lesions in Southern Brazil. Arq. Bras. Med. Vet. Zootec. 53:654-657.

Cunha C.S.T. 2010. Prevalência das afecções podais em explorações de bovinos leiteiros com pavimento de cimento liso versus ripado. Disserta- 
ção de Mestrado Integrado em Medicina Veterinária, Universidade de Trás-os-Montes e Alto Douro, Vila Real, Portugal. 80p.

Dirksen G. 2008. Sistema digestivo, p.166-228. In: Dirksen G., Gründer H. \& Stöber M. (Eds), Exame Clínico dos Bovinos. 3a ed. Guanabara Koogan, Rio de Janeiro.

Dohme F., DeVries T.J. \& Beauchemin K.A. 2008. Repeated ruminal acidosis challenges in lactating dairy cows at high and low risk for developing acidosis: ruminal pH. J. Dairy Sci. 91:3554-3567.

Feitosa L.F.F. 2008. Semiologia Veterinária: a arte do diagnóstico. $2^{a}$ ed. Roca, São Paulo. 735p.

Ferreira P.M., Carvalho A.U., Facury-Filho E.J., Ferreira M.G. \& Ferreira R.G. 2005. Afecções do sistema locomotor dos bovinos. Simpósio Mineiro de Buiatria, Belo Horizonte, MG. 26p.

Ferreira P.M., Leite R.C., Carvalho A.U., Facury-Filho E.J., Souza R.C. \& Ferreira M.G. 2004. Custos e resultados do tratamento de sequelas de laminite bovina: relato de 112 casos em vacas em lactação no sistema free-stall. Arq. Bras. Med. Vet. Zootec. 56:589-594.

Gianesella M. 2008. Subacute rumen acidosis in Italian dairy herds: occurrence and diagnostics tools. Scuola Di Dottorato Di Ricerca in Scienze Veterinarie, Indirizzo Scienze Cliniche Veterinarie, XXo Ciclo, Facolta Di Medicina Veterinaria, Universita degli Studi di Padova, Itália. 90p.

Gozho G.N., Krause D.O. \& Plaizier J.C. 2007. Ruminal lipopolysaccharide concentration and inflammatory response during grain-induced subacute ruminal acidosis in dairy cows. J. Dairy Sci. 90:856-866.

Greenough P.R. 2007. Bovine Laminitis and Lameness: a hands-on approach. Elsevier, Philadelphia. 311p.

Hernandez J.A., Garbarino E.J., Shearer J.K., Risco C.A. \& Thatcher W.W. 2005. Comparison of milk yield in dairy cows with different degrees of lameness. J. Am. Vet. Med. Assoc. 227:1292-1296.

Hernandez J., Shearer J.K. \& Webb D.W. 2002. Effect of lameness on milk yield in dairy cows. J. Am. Vet. Med. Assoc. 220:640-644.

Kaneko J.J., Harvey J.W. \& Bruss M.L. 1997. Clinical Biochemistry of Domestic Animals. $5^{\text {th }}$ ed. Academic, San Diego, EUA. 932p.

Krause K.M. \& Oetzel G.R. 2005. Inducing subacute ruminal acidosis in lactating dairy cows. J. Dairy Sci. 88:3633-3639.

Lavezzo O.E.N.M., Faria V.P., Mattos W.R.S. \& Lavezzo W. 1988. Influência de métodos de coleta de fluido ruminal sobre os parâmetros de fermentação em bovinos alimentados com diferentes fontes de proteína. Revta Soc. Bras. Zootec. 17:281-291.

Lisbôa J.A.N., Benesi F.J., Leal M.L.R. \& Teixeira C.M.C. 2002. Efeito da idade sobre o equilíbrio ácido-básico de bezerras sadias no primeiro mês de vida. Braz. J. Vet. Res. Anim. Sci. 39:136-142.

Lodge-Ivey S.L., Browne-Silva J. \& Horvath M.B. 2009. Technical note: Bacterial diversity and fermentation end products in rumen fluid samples collected via oral lavage or rumen cannula. J. Anim. Sci. 87:2333-2337.

Machado P.P., Morais P.H., Santos H.P., Oliveira R.A., Guerra P.C. \& Teixeira W.C. 2008. Prevalência e classificação de afecções podais em fêmeas bovinas destinadas à produção de leite na bacia leiteira do município de Itapecuru Mirim-MA. Revta Bras. Saúde Prod. Anim. 9:777-786.

Martins C.F., Sarti E., Busato I., Pires P.P., Fiori C.H., Moreira C., Soares K., Betini B. \& Velasquez M. 2002. Prevalência e classificação das afecções podais em vacas lactantes na bacia leiteira de Campo Grande (Capital) e municípios arredores, MS. Ensaios e Ciência 6:113-137.

Mason W.A., Laven L.J. \& Laven R.A. 2012. An outbreak of toe ulcers, sole ulcers and White line disease in a group of dairy heifers immediately after calving. N.Z. Vet. J. 60:76-81.

Mazrier H., Tal S., Aizinbud E. \& Bargai U. 2006. A field investigation of the use of the pedometer for the early detection of lameness in cattle. Can. Vet. J. 47:883-886.

Meyer D.J., Coles E.H. \& Rich L.J. 1995. Medicina de Laboratório Veterinária: interpretação e diagnóstico. Roca, São Paulo. 308p.

Molina L.R., Carvalho A.U., Facury-Filho E.J. \& Ferreira P.M. 1999. Prevalência e classificação das afecções podais em vacas lactantes na bacia leiteira de Belo Horizonte. Arq. Bras. Med. Vet. Zootec. 51:149-152.

Mulling C.K.W., Green L., Barker Z., Scaife J., Amory J. \& Speijers M. 2006.
Risk factors associated with foot lameness in dairy catte and suggested approach for lameness reduction. XXIV World Buiatrics Congress, Nice, France. 12p.

Murray R.D., Downham D.Y., Carkson M.J., Faull W.B., Hughes J.W., Manson F.J., Merrit J.B., Russel W.B., Sutrherst Y.E. \& Ward W.R. 1996. Epidemiology of lameness in dairy cattle: description and analysis of foot lesions. Vet. Rec. 138:586-591.

Nicoletti J.L.M. 2004. Manual de Podologia Bovina. Manole, São Paulo. $126 \mathrm{p}$.

Nordlund K.V., Cook N.B. \& Oetzel G.R. 2004. Investigation strategies for laminitis problem herds. J. Dairy Sci. 87:E27-E35.

Ortolani E.L. 2003. Diagnóstico e tratamento de alterações ácido-básicas em Ruminantes, p.17-28. In: González F.H.D. \& Campos R. (Eds), Anais I Simpósio de Patologia Clínica Veterinária da Região Sul do Brasil. Faculdade de Veterinária, Universidade Federal do Rio Grande do Sul, Porto Alegre. 102p.

Peiro R.J., Borges A.S., Gonçalves R.C. \& Mendes L.C.N. 2010. Evaluation of a portable clinical analyzer for the determination of blood gas partial pressures, electrolyte concentrations, and hematocrit in venous blood samples collected from cattle, horses, and sheep. Am. J. Vet. Res. 71:515-521.

Radostits O.M. 2002. Clínica Veterinária: um tratado de doenças dos bovinos, ovinos, suínos, caprinos e equinos. 9ae ed. Guanabara Koogan, Rio de Janeiro. 1737p.

Rama J.M.R. 2006. Risk factors of lameness in dairy cattle and its interaction with the grazing ecosystem of milk production. $14^{\text {th }}$ International Symposium and $6^{\text {th }}$ Conference on Lameness in Ruminants, Uruguay. 73p.

Rangel A.H.N., Campos J.M.S., Oliveira A.S., Filho S.C.V., Assis A.J. \& Souza S.M. 2010. Desempenho e parâmetros nutricionais de fêmeas leiteiras em crescimento alimentadas com silagem de milho ou cana-de-açucar com concentrado. Revta Bras. Zootec. 39:2518-2526.

Sagliyan A., Gunay C. \& Han M.C. 2010. Prevalence of lesions associated with subclinical laminitis in dairy cattle. Israel J. Vet. Med. 65:27-33.

Salles M.S.V., Zanetti M.A., Del Claro G.R., Netto A.S. \& Franzolin R. 2003. Avaliação de colheita de líquido ruminal por fístula ou sonda esofágica em bovinos. Arq. Bras. Med. Vet. Zootec. 55:438-442.

Silva F.F., Alves C.G.T. \& Silva Júnior F.F. 2006. Pododermatite solar circunscrita, úlcera de husterholz ou úlcera da sola. Ciênc. Vet. Tróp. 9:102-105.

Silva L.A.F., Silva L.M., Romani A.F., Rabelo R.E., Fioravanti M.C.S., Souza T.M. \& Silva C.A. 2001. Características clínicas e epidemiológicos das enfermidades podais em vacas lactantes do município de Orizona/GO. Ciênc. Anim. Bras. 2:119-126.

Silveira J.B., Menechelli A.A. \& Andrade E.F. 1999. Levantamento epidemiológico das principais afeç̧ões podais em bovinos no município de Votuporanga/SP. Ciênc. Vet. 2:18-19.

Silverman S.C. \& Birks E.K. 2002. Evalution of the i-STAT hand-held chemical analyser during treadmill and endurance exercise. Equine Vet. J. 34:551-554.

Somers J.G.C.J., Frankena K., Noordhuizen-Stassen E.N. \& Metz J.H.M. 2003. Prevalence of claw disorders in dutch dairy cows exposed to several floor systems. J. Dairy Sci. 86:2082-2093.

Stone W.C. 2004. Nutritional approaches to minimize subacute ruminal acidosis and laminitis in dairy cattle. J. Dairy Sci. 87:E13-E26.

Sucupira M.C.A. \& Ortolani E.L. 2003. Uso de sangue arterial e venoso no exame do equilíbrio ácido-básico de novilhos normais ou com acidose metabólica. Ciência Rural 33:863-868.

Taijk J., Nadalian M.G., Raoofi A., Mohammadi G.R. \& Bahonar A.R. 2009. Prevalence of subacute ruminal acidosis in some dairy herds of Khorasan Razavi province, northeast of Iran. Iranian J. Vet. Res. 10:28-32.

Underwood W.J. 2002. Pain and distress in agricultural animals. J. Am. Vet. Med. Assoc. 221:208-211.

Warnick L.D., Janssen D., Guard C.L. \& Grohn Y.T. 2001. The effect of lameness on milk production in dairy cows. J. Dairy Sci. 84:1988-1997.

Zilio R.S., Cruz E.D.V., Andrade Júnior J.P., Merlini G.P., Duque P.V.T. \& Sacco S.R. 2008. Análise do liquido ruminal - revisão de literatura. Revta Cient. Eletr. Med. Vet. 11:1-6. 